\title{
Technological change dynamic and learning curve theory: application to the global energy system
}

\author{
S. Kahouli-Brahmi \\ Université de Nantes, Faculté des sciences économiques et de gestion, \\ Laboratoire d'économie de Nantes (LEN), France
}

\begin{abstract}
This paper has two goals. First, to explain the sources of an energy system lock-in. Second, to analyse the factors for creating conditions for technological path-breaking. We present a comparative analysis of the respective contributions of the learning-by-doing, the learning-by-researching and returns to scale effects in explaining the technological change dynamic. Our analysis is articulated within the increasing returns to adoption hypothesis of Arthur (Competing technologies, increasing returns, and lock-in by historical events. The economic journal 99, pp. 116-131, 1989) and is based on the learning curve theory. Global time series data of nine energy technologies, conventional and renewable, were collected. Causality analysis and econometric estimation of learning rates and scale effects were performed. The results show that learning effects have been an important source of cost decrease and thus of learning system performance improvements. They also show that the magnitude of the learning effects as well as of the scale effects depend on the technological change stage of energy technologies. Based on major results, some theoretical institutional and policy issues inherent to the energy market barriers and to the conditions for creating technological path-breaking are also assessed and discussed.

Keywords: technological change, energy diffusion, two factor learning curve, returns to scale effect, energy lock-in, increasing returns to adoption.
\end{abstract}

\section{Introduction}

Environmental policy debates increasingly focus on issues related to energy system dynamics. For a long time, production and consumption processes have been based on fossil fuel resources, mainly oil and coal energy technologies, 
which have serious harmful effects on the environment and the ecosystem equilibrium. Subsequently, the major challenge of the international community is to shift from a conventional energy-based economic system to an environmentally friendly-based economic system in order to avoid ecological system degradation. However, the environmentally friendly technologies correspond to a techno-economic system that is radically different from a conventional techno-economic system in terms of structure, density, needed investment and regulatory practices (Tsoutsos and Stamboulis [1]). Therefore, the transition process which starts with the development and then the deployment of renewable energy innovations, goes beyond the simple substitution of energy technologies' use and basically corresponds to a change in the path and direction of technological change regimes. Until now, the technological transition process supposed to have started a few decades ago, is still uncompleted and shows some serious hitches related especially to the low competitiveness of the renewable energy technologies and to the established market structure. Indeed, the actual energy system is locked-in to the conventional fossil fuel resources which benefit from important increasing returns to adoption factors (Arthur [2]) and the technological regime shift to renewable energy sources exhibits large systemic barriers. It is, thus, of interest to enhance our understanding of factors that promote the technological regime transition and create favourable conditions for path-breaking.

In this paper, we use the learning curve approach to investigate these issues in the framework of technological change dynamics. We perform a comparative analysis between the conventional and the renewable energy systems in order to find out factors likely to explain the path-dependence observed phenomena and to assess conditions for technological regime transition. We are interested in nine learning systems: three correspond to conventional energy technologies and five correspond to renewable energy technologies. In addition to the learning effects, we pay special attention to scale effects estimation since they are shown to be partly responsible for the lock-in of the system. The theoretical framework of the analysis is addressed in Section 2. The model specification and the data description and source are presented in Section 3. The econometric approach and results discussion are given in Section 4. Section 5 gives the major policy directions. Finally, summary and concluding remarks are formulated in Section 6.

\section{Theoretical framework of the analysis}

The intensive reliance on the conventional energy sources has engendered both environmental degradation and resource scarcity. Therefore, the transition to a non-harmful and sustainable energy system based on renewable energy technologies appears as an urgent challenge.

The technological transition or shift concept refers to multilevel changes involved when a given sector is moved from one quasi-stable configuration through a number of phases and translations to another quasi-stable configuration (Jorgensen [3]). Despite the accepted wisdom of the advantages of 
the renewable energy technologies and their exhibited performance, the transition to a sustainable energy process still faces considerable challenges due to the radical divergence between the knowledge bases supporting the two technological regimes. The major challenge is therefore to develop a new learning network associated with an appropriate selection environment that focuses on adequate technology policy definition, and is able to enhance the adoption and the diffusion of renewable energy technologies. Nevertheless, the Arthur hypothesis states that the adoption process is stressed by some increasing returns to adoption factors which are learning effects, economies of scale, network externalities, increasing returns of information and technological interdependencies. Once a given technology is produced and adopted for the first time, it acts as a self-reinforcing mechanism and brings about a new technological trajectory supported in the long-run by the possible development of a new selection environment (Arthur [2]). On the basis of the theoretical framework of Arthur [2] about the technological competing models and the increasing returns to adoption hypothesis, we aim to check if there are really increasing returns to adoption mechanisms that have supported the adoption of conventional energy resources to the detriment of renewable energy. We aim also to compare the strength of these self-reinforcing mechanisms between the two technological regimes. In our analysis the learning effects and the returns to scale are considered. Their estimation and their quantification are based on the two factor learning curve (TFLC) modelling.

\section{Learning curve modelling}

The purpose of the following section is to present the learning curve specification and a preliminary qualitative data description and sources. The derivation of the TFLC functional forms is based on the production and the duality theory and allow for the simultaneous estimation of learning and returns to scale effects. In the following, the learning effects are understood to be related to cumulative production and to knowledge stock accumulations issued from $\mathrm{R} \& \mathrm{D}$ expenditures and are assumed to be estimated separately from the returns to scale.

\subsection{Model specification}

The following description is based on Berndt [4]. To specify the functional form of the learning curve, which will be estimated, we start by characterizing a production function for energy producer using a Cobb-Douglas specification:

$$
Y=A \cdot l^{\alpha} k^{\beta} \text { where } 0<\alpha<1,0<\beta<1 \text { and } A>0
$$

where $Y$ is the output, $l$ is the labour input, $k$ is the capital input, and $A$ is the technological change. The prices are constant. The total cost is: 


$$
C=p_{l} l+p_{k} k
$$

where $p_{l}$ is the labour price, and $p_{k}$ is the capital price. The cost minimization program consists of minimizing the cost subject to the production function:

$$
\min C=p_{l} l+p_{k} k \text { subject to } Y=A \cdot l^{\alpha} k^{\beta}
$$

If we replace $l$ and $k$ by their expressions in the total cost expression, we obtain the following expression:

$$
C=A^{-\frac{1}{\alpha+\beta}} \cdot Y^{\frac{1}{\alpha+\beta}} \cdot p_{k}^{\frac{\beta}{\alpha+\beta}} \cdot p_{l}^{\frac{\alpha}{\alpha+\beta}} \cdot a
$$

$\alpha$ and $\beta$ represent the scale effects. The main two drivers of endogenous technological change, represented by the $A$ parameter, are the learning-by-doing and the learning-by-researching. The R\&D expenditures (public and private) permit one to define the knowledge stock, which will be calculated on the basis of the following equation:

$$
K S_{t}=(1-\delta) \cdot K S_{t-1}+R \& D_{t-x}
$$

where $K S_{t}$ is the knowledge stock at time $t, \mathrm{R} \& \mathrm{D}_{t}$ are the $\mathrm{R} \& \mathrm{D}$ expenditures at time $t, \delta$ is the annual depreciation rate of knowledge stock and $x$ is time lag for adding $\mathrm{R} \& \mathrm{D}$ to the knowledge stock. The $A$ parameter is defined as follows:

$$
A=Q^{-\lambda} K S^{-\delta} \quad \text { where } \lambda<0 \text { and } \delta<0
$$

where $Q$ is the cumulative installed capacity and $K S$ is the knowledge stock inherent to public and private $R \& D$ investments. $\lambda$ represents the elasticity of the production to cumulative production and $\delta$ the elasticity of the production to cumulative R\&D expenditures. The two parameters $\lambda$ and $\delta$ therefore represent respectively the learning-by-doing and learning-by-researching rate. If we substitute equation (6) in equation (4) and if we assume that the inflationary effect of input prices can be taken into account by GNP deflator defined as:

$$
p_{k}^{\frac{\beta}{\alpha+\beta}} \cdot p_{l}^{\frac{\alpha}{\alpha+\beta}}
$$

we obtain the following unitary cost function: 


$$
c=Q^{\frac{\lambda}{\alpha+\beta}} \cdot K S^{\frac{\delta}{\alpha+\beta}} \cdot Y^{\frac{1-(\alpha+\beta)}{\alpha+\beta}} \cdot a
$$

The equation that will be econometrically estimated is:

$$
\begin{aligned}
& \log c=\left(\frac{\lambda}{\alpha+\beta}\right) \log Q+\left(\frac{\delta}{\alpha+\beta}\right) \log K S+\left(\frac{1-(\alpha+\beta)}{\alpha+\beta}\right) \log Y \\
& +\log a+\varepsilon
\end{aligned}
$$

where $\varepsilon$ is an error term, $c$ is the per-unit cost, $Q$ is the cumulative installed capacity, $K S$ is the knowledge stock and $Y$ is the power generation capacity. The learning elasticities and the scale effects are calculated as follows:

$$
\alpha+\beta=\frac{1}{1+\psi} \text { where } \psi=\frac{1-(\alpha+\beta)}{\alpha+\beta}, \lambda=(\alpha+\beta) \cdot \mu
$$

where

$$
\mu=\frac{\lambda}{\alpha+\beta} \text { and } \delta=(\alpha+\beta) \cdot \eta \text { where } \eta=\frac{\delta}{\alpha+\beta}
$$

\subsection{Data description and sources}

Global time series data of nine energy technologies were collected. They correspond to eleven regions in the world. Energy technologies were divided into two groups: conventional energy technologies and renewable energy technologies. These two groups are also divided into three subsamples: mature, evolving and emerging technologies. The database was provided by the LEPIIEPE (Laboratoire Economie Politique de l'Intégration Internationale et du Développement-Energie et Politique de l'Environnement), Grenoble, France. It has been assembled in the framework of the SAPIENT project (DG Research) to inform the world energy simulation model, POLES.

The time series data needed for our estimations are provided in table 1.

Table 1: Description of the data.

\begin{tabular}{|c|c|}
\hline Data & Unity \\
\hline Power generation capacities & MWe \\
\hline Government energy R\&D & M\$98 \\
\hline Public knowledge stock & M\$98 \\
\hline Business energy R\&D & M\$98 \\
\hline Business knowledge stock & M\$98 \\
\hline Energy technology cost & $\$ 90 / \mathrm{kWe}$ \\
\hline
\end{tabular}




\section{Econometric estimation and result interpretation}

The results of the econometric estimations are addressed in tables 2 and 3 . We have used the OLS multiple regression technique. Detection of the possible multicolinearity among the explanatory variables was undertaken based on the Klein [5] test and the correlation matrix shows that no evidence of multicolinearity is suggested. The homescedasticity and independence conditions of residuals are also checked out. For the homescedasticity condition, we based on the White [6] test and for the residuals autocorrelation are based on Durbin and Watson [7] test, Breusch [8] test and Godfrey [9] test. The results show that the residuals are independent and identically distributed for all regressions.

For the first two estimations, which correspond to coal and lignite conventional technologies, the returns to scale range from 1.076 to 1.326 meaning that increasing returns to scale may have taken place at the outset of the development and the deployment stages. The increasing returns to scale imply that these technologies face less market constraints in terms of commercial and expansion opportunities. They are, therefore, expected to be mature technologies that have reached the large diffusion stage. However, despite their mainstream position and widespread use, these technologies have low learning-by-doing and learning-by-researching rates, which range respectively from $2.80 \%$ to $5.32 \%$ and from $1.25 \%$ to $3.08 \%$. This is not surprising since they are situated in the last stage of a technological change process: the diffusion and large scale deployment stage. Indeed, when technology is mature a doubling of cumulative installed capacity can take place rather slowly and over a long period of time due to saturation effects meaning that the prospects of cost reduction become limited. In the same way, the R\&D expenditures flows are the least important compared to flows corresponding to an energy technology in the first stage of technological development process and, as consequence, the knowledge stock increases slowly.

Table 2: Learning and scale effects estimation for conventional energy technologies.

\begin{tabular}{|c|c|c|c|}
\hline Index & CCT & LCT & NUC \\
\hline 1. $Y$ & $\begin{array}{c}-0.246 \\
(-9.340)^{* * *}\end{array}$ & $\begin{array}{c}-0.071 \\
(-2.972)^{* * *}\end{array}$ & $\begin{array}{c}0.098 \\
(4.062)^{* * *}\end{array}$ \\
\hline 2. $Q$ & $\begin{array}{c}-0.060 \\
(-3.668) * * *\end{array}$ & $\begin{array}{c}-0.039 \\
(-2.348)^{* *}\end{array}$ & $\begin{array}{c}-0.279 \\
(-6.103) * * *\end{array}$ \\
\hline 3. $S C$ & $\begin{array}{c}-0.013 \\
(-4.990)^{* * *}\end{array}$ & $\begin{array}{c}-0.042 \\
(-2.510)^{* *}\end{array}$ & $\begin{array}{c}-0.212 \\
(-2.279)^{* *}\end{array}$ \\
\hline RS & 1.326 & 1.076 & 0.910 \\
\hline LBD elasticity & -0.079 & -0.041 & -0.254 \\
\hline LBS elasticity & -0.018 & -0.045 & -0.193 \\
\hline LBD rate & $5.32 \%$ & $2.80 \%$ & $16.14 \%$ \\
\hline LBS rate & $1.25 \%$ & $3.08 \%$ & $12.53 \%$ \\
\hline Adjusted $\mathrm{R}^{2}$ & 0.967 & 0.959 & 0.581 \\
\hline $\begin{array}{l}\text { Number of } \\
\text { observations }\end{array}$ & 31 & 31 & 31 \\
\hline
\end{tabular}

$* * *$ significant at $1 \%, * *$ significant at $5 \%,{ }^{*}$ significant at $10 \%$. 
The third non-renewable energy technology analysed, the light water nuclear reactors, present, in contrast, decreasing returns to scale and relatively high learning rates. The results are different from those obtained for the coal and lignite conventional energy technologies because the light water nuclear reactors technology is considered to be evolving rather than mature. More accurately, high learning rates are explained by the relatively short period of time needed for the doubling of cumulative installed capacity and by the increasing rate of R\&D devoted to support the development of light water nuclear reactors. Indeed, they represent $86 \%$ of the functioning park and $79 \%$ of the park under consideration and have a large prospect for development. However, the decreasing returns to scale means that despite the fact that the nuclear technology benefits from the experience effects of doubling of cumulative installed capacities and from R\&D flows, it still faces serious barriers to market diffusion inherent especially to nuclear accidents and to radioactive wastes. Compared to the renewable energy technologies, it does not appear as a priority in energy policy and environmental concerns despite its considerable participation in the provision of electricity.

We conclude, therefore, that differences in learning rates and returns to scale effects between the three energy technologies, which are classified in the category of non-renewable energy technologies, are mainly due to the differences in their technological change stage. Other technology properties, like the environmental or the economic characteristics can largely influence the diffusion rate of energy technologies.

Table 3: Learning and scale effects estimation for renewable energy technologies.

\begin{tabular}{|c|c|c|c|c|c|c|}
\hline Index & WND & BF2 & DPV & RPV & SPP & HYD \\
\hline 1. $Y$ & $\begin{array}{c}0.068 \\
(5.752)^{* * *}\end{array}$ & $\begin{array}{c}-0.879 \\
(-1.709)\end{array}$ & $\begin{array}{c}0.148 \\
(2.461)^{*} \\
*\end{array}$ & $\begin{array}{c}0.157 \\
(2.536)^{*} \\
*\end{array}$ & $\begin{array}{c}0.391 \\
(-2.893)^{* *}\end{array}$ & $\begin{array}{c}-0.036 \\
(-2.571)^{* *}\end{array}$ \\
\hline 2. $Q$ & $\begin{array}{c}-0.332 \\
(-7.605)^{* * *}\end{array}$ & $\begin{array}{l}-1.381 \\
(-0.908)\end{array}$ & $\begin{array}{c}-0.075 \\
(- \\
1.735)^{*}\end{array}$ & $\begin{array}{c}-0.079 \\
(- \\
2.284)^{*} \\
*\end{array}$ & $\begin{array}{c}0.317 \\
(5.587)^{* *}\end{array}$ & $\begin{array}{c}-0.061 \\
(- \\
10.115)^{* *} \\
*\end{array}$ \\
\hline 3. $S C$ & $\begin{array}{c}-0.278 \\
(-8.119)^{* * *}\end{array}$ & $\begin{array}{c}-0.718 \\
(-1.440)\end{array}$ & $\begin{array}{c}-0.063 \\
(- \\
4.592)^{*} \\
* *\end{array}$ & $\begin{array}{c}-0.067 \\
(- \\
3.495)^{*} \\
* *\end{array}$ & $\begin{array}{c}-0.085 \\
(-2.496)^{* *}\end{array}$ & $\begin{array}{c}-0.014 \\
(- \\
17.545)^{* *} \\
*\end{array}$ \\
\hline RS & 0.936 & -- & 0.871 & 0.864 & 0.718 & 1.037 \\
\hline $\begin{array}{c}\text { LBD } \\
\text { elasticity }\end{array}$ & -0.311 & -- & -0.065 & -0.068 & -- & -0.064 \\
\hline LBS elasticity & -0.260 & -- & -0.054 & -0.057 & -0.061 & -0.014 \\
\hline LBD rate & $19.41 \%$ & -- & $4.40 \%$ & $4.62 \%$ & -- & $4.35 \%$ \\
\hline LBS rate & $16.52 \%$ & -- & $3.67 \%$ & $3.87 \%$ & $4.14 \%$ & $1 \%$ \\
\hline Adjusted $\mathrm{R}^{2}$ & 0.985 & 0.326 & 0.976 & 0.974 & 0.681 & 0.993 \\
\hline Observations & 31 & 12 & 31 & 21 & 16 & 31 \\
\hline
\end{tabular}

The estimation results of renewable energy technologies group are presented in table 3. The wind energy technology, which is an evolving technology, presents almost the same scheme evolution as the light water nuclear reactors 
technology. The learning-by-doing and the learning-by-researching levels are high and respectively equal to $19.41 \%$ and $16.52 \%$. However, despite the considerable growth trend of cumulative installed capacity associated with the continuous knowledge stock increase and considerable subsequent cost decrease, the wind energy technology still faces important and several market barriers in reaching a significant share of electricity resource mix. Indeed, estimated returns to scale are equal to 0.936 , which implies that this technology is subject to diseconomies of scale related especially to the lack of full cost competitiveness and to the reliance on public subsidies. Therefore, wind energy technology needs more specific technology policies to go up beyond the early beginning stage of technological change and to reach the maturity stage like, for instance, large hydropower energy technology. The latter represents one of the oldest renewable energy technology developed and utilised over a long period and has a major role in the electricity sector. It has accomplished large-scale deployment schemes and it is considered, therefore, a mature energy technology. This is ensured by scale effects estimation, which shows that large hydropower technology has benefited from economies of scale. On the other hand, estimations show a low level of learning effects meaning that the technology continues to evolve but at a slower rate. In general, hydropower energy technology exhibits the same characteristics as coal and lignite energy technologies.

The decentralized and the rural photovoltaic energy technologies, which are both emerging technologies, have existed for a relatively short time and have achieved a lower degree of technological change progress during the period under consideration. This is why they have decreasing returns to scale and low learning rates: returns to scale range from 0.864 to 0.871 and the learning-bydoing and learning-by-researching range respectively from $4.40 \%$ to $4.62 \%$ and from $3.67 \%$ to $3.87 \%$. As in the precedent cases, decreasing returns to scale means that technologies under consideration face barriers to diffusion greatly caused by their high investment costs and their low competitiveness potential. The low level of learning rates is interpreted as a lack of cost responsiveness to capacity expansion and also to R\&D efforts. As a result of market barriers and low cost competitiveness, the technological change dynamic of emerging technologies has been slow and they are yet to gain a noticeable share of energy mix.

The solar thermal power plant technology, which is also an emerging energy technology, presents almost the same schemes as the decentralized and rural photovoltaic energy technologies: decreasing returns to scale effects and low learning-by-researching rate. Nevertheless, the learning-by-doing rate is not calculated because of the problem of wrong sign, which is current in the literature estimating learning curve. The electricity production from waste estimation results cannot be interpreted because the coefficients are not significant.

In sum, results of our estimations show that the main explicative factors of the differences in learning rates and returns to scale effects between the several considered energy technologies is their technological change stage characteristic: mature, evolving or emerging. Mature and emerging technologies present both 
low learning effects, but the former has increasing returns to scale due to its large scale adoption and the latter has decreasing ones because of barriers to marketbased diffusion. The evolving technologies are situated in an intermediate situation between the mature and the emerging technologies and show a relatively high estimated level of learning rates, which means that they respond positively to diffusion promotion policy and that they have important opportunities of adoption.

With regard to the Arthur hypothesis, when we compare the path diffusion of the conventional energy technologies to renewable energy technologies, we can argue that the observed lock-in and path-dependence situation on the conventional fuel resources is justified by the presence of increasing returns to adoption factors mainly in the form of economies of scale which act as selfreinforcing mechanisms and prevent the technological regime shift. The relationship is, thus, significant between increasing returns to adoption factors and the adoption decision. The renewable energy technologies seem to be unable to compete with the established energy system as long as the learning process is not achieved and conditions for technological path-breaking are not conceived.

\section{Major policy directions}

To overcome the several barriers to entry (technological, economic, societal and behavioural and regulatory), the transition process of renewable energy technologies should be boosted from the emergence stage to its self-sustaining growth path on the basis of both technology-push and demand-pull measures. These two complementary measures permit to enhance the learning system performance. The aim of technology-push measures is to overcome such barriers and to promote generation of the knowledge flows and development of technologies which are in the early stage of technological change process, whereas the aim of the demand-pull measures is to promote technical change by creating demand and developing markets for new innovative technologies and products. The combination of the two technology policy measures permits to overcome the supply and demand market barriers to entry, but the challenge still is to put policies in place and to ensure their synergy effects. At the basic stage, the technology push measures, like the government R\&D as well as the financial support schemes (subsidies, tax credit...), are initially more important. As the energy technologies mature, policies supporting demand-pull will gradually be more effective in promoting technological progress. The compatibility between technological policies and the technological progress stage of the technology is hence crucial.

In this context, technology policies supporting the transition process should rely on three policy directions. First, the development of focused micro and macro learning mechanisms. Second, the encouragement of new types of players and third the definition of flexible financing mechanisms, adapted to the characteristics of individual applications and environmentally consistent economic evaluation. Kamp [10] and Weber \& Dorda [11] propose a new penetration-promotion approach based on these three directions for the transition 
to a new technological regime called the strategic niche management approach. It is mainly based on the creation of protected spaces for the development and use of new technologies to conceive conditions for interactive learning that may extend beyond the individual technologies. Weber \& Dorda [11] stress that the niche market approach contributes to the articulation of radical innovations, which may affect the structure of the conventional system and enhance the market diffusion process of the renewable energy by putting together the technological development with the institutional and organizational change, which are necessary for the success of technology. The market niche strategy provides an integrated approach, which merges the technology-push measures with the demand-pull in a unique evolving system.

\section{Summary and concluding remarks}

The paper has two goals: to explain the sources of energy system lock-in and to analyse the factors for creating conditions for path-breaking. The results show that learning effects have been an important factor for cost decrease and thus for learning system performance improvements. They also show that the renewable energy technologies analysed present a potentially important prospect of diffusion, but require initial support from the technological policies before taking full economic and environmental advantages of the technological change regime shift.

At the end of this paper, it is important, however, to note that from a methodological point of view some remarks are suggested. Indeed, technology learning rates are often based on econometric estimations of relatively short time series data where all series exhibit strong trends. This can engender several problems that seriously affect the quality of estimations. First, it is possible that some estimated elasticities could be statistically insignificant or even have an unintuitive sign (Cory et al. [12]). Second, the results of regressions could be spurious and the R-squares could overestimate the relationship between the endogenous and the exogenous variables. Moreover, despite its contribution in enhancing our understanding of the technological change dynamic in energy sector, the TFLC specification is still limited especially when trying to model some special effects as endogeneity effects between the cumulative installed capacity and the unit cost. The extension of the TFLC functional form should help to take account of these observed phenomena. Refining the data and the methodology permits to avoid econometric problems and strongly contributes to enhance our understanding of the energy technologies dynamic.

\section{References}

[1] Tsoutsos, T. \& Stamboulis, Y., The sustainable diffusion of renewable energy technologies as an example of an innovation-focused policy. Technovation 25, pp. 753-761, 2005.

[2] Arthur, B., Competing technologies, increasing returns, and lock-in by historical events. The economic journal 99, pp. 116-131, 1989. 
[3] Jorgensen, U., Energy sector in transition: technologies and regulatory policies in flux. Technological forecasting and social change 72, pp. 719731, 2005.

[4] Berndt, E., The practice of econometrics: classical and contemporary. Addison-Wesley Publishing, Boston, MA, 1996.

[5] Klein, L., An introduction to econometrics. Prentice Hall, 1962.

[6] White, H., A heteroscedasticity-consistent covariance estimator and a direct test for heteroscedasticity. Econometrica 48(4), pp. 817-838, 1980.

[7] Durbin, J. \& Watson, G. S., Testing for serial correlation in last squares regression. Biometrika 38, pp. 201-223, 1951.

[8] Breusch, T., Testing for autocorrelation in dynamic linear models. Australian economic paper 17, pp. 334-356, 1978.

[9] Godfrey, L. G., Testing fir higher order serial correlation in regression equation when the regressor contain lagged dependant variables. Econometrica 46(6), pp. 1303-1310, 1978.

[10] Kamp, L., Learning in wind turbine development. A comparison between the Netherlands and Denmark. Doctorate thesis, Utrecht University, 2002.

[11] Weber, M. \& Dorda, A., Strategic niche management: a tool for the market introduction of new transport concepts and technologies. IPTS Report, 1998.

[12] Cory, K., Bernow, S., Dougherty, W., Kartha, S. \& Williams, E., Analysis of wind turbine cost reductions: the role of research and development and cumulative production. AWEA's WINDPOWER conference, Burlington, VT, June 22, 1999. 